\title{
o.
}

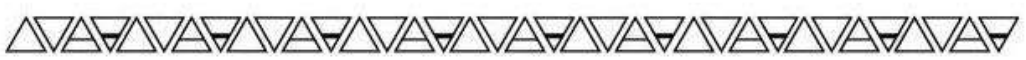

DOI 10.31418/2177-2770.2020.v12.n.31.p95-112 | ISSN 2177-2770 Licenciado sob uma Licença Creative Commons

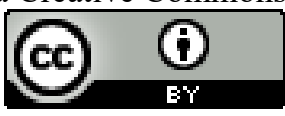

\section{A FILOSOFIA DO MALANDRO: ESTÉTICAS DE UM CORPO ENCANTADO PELA DESOBEDIÊNCIA}

\author{
Laudemir Pereira dos Santos (Lau Santos) ${ }^{1}$
}

Resumo: O objetivo deste artigo é provocar reflexões sobre o aspecto filosófico do jogo de corpo da malandragem como um ato de resistência aos saberes hegemônicos eurocentrados. Proponho-me, portanto, a versar sobre a malandragem como um gesto étnico-racial de desobediência ao colonialismo. Observo que este comportamento afrorreferenciado é atravessado por grafias corporais geradoras de outras lógicas epistemológicas para além do cartesianismo. Duas questões suleiam minhas reflexões neste artigo: Seria o jogo de corpo do sujeito chamado de malandro, uma estratégia filosófica para desobedecer aos padrões coloniais de comportamento? Qual seria a razão dos termos malemolência e pelintra, que fazem parte do vocabulário da cultura afrobrasileira, serem abordados de forma preconceituosa e depreciativa nos dicionários de língua portuguesa?

Palavras-chave: Corpo; Malandro; Decolonial; Capoeira; Samba.

\section{THE MALANDER'S PHILOSOPHY: AESTHETICS OF A BODY ENCHANTED BY DISOBEDIENCE}

\begin{abstract}
The aim of this article is to provoke reflections on the philosophical aspect of the trickster's body game as an act of resistance to Eurocentric hegemonic knowledge. I propose, therefore, to deal with trickery as an ethnic-racial gesture of disobedience to colonialism. I observe that this afrorreferenced behavior is crossed by body spellings that generate other epistemological logics in addition to Cartesianism. Two questions underlie my reflections in this article: Would the subject's body game be called a trickster, a philosophical strategy to disobey colonial patterns of behavior? What would be the reason for the terms, malemolence and pelintra, which are part of the vocabulary of AfroBrazilian culture, to be approached in a prejudiced and derogatory way in Portugueselanguage dictionaries?
\end{abstract}

Keywords: Body; Malander; Decolonial; Capoeira; Samba.

\section{LA FILOSOFÍA DEL MALANDRO: ESTÉTICA DE UN CUERPO ENCANTADO POR LA DESOBEDIENCIA}

\footnotetext{
${ }^{1}$ Diretor, Ator, Capoeirista, Performer, Professor e Pesquisador na área das Artes Cênicas. Doutor e Mestre em Teatro pela Universidade de Estadual de Santa Catarina (UDESC). Pós-Doutorado em Dança pela Universidade Federal da Bahia (UFBA). Professor da Escola de Teatro (UFBA). Pesquisador do Grupo de Pesquisas Rede Africanidades (UFBA) e do GIRA (UFBA). E-mail: lau ator@hotmail.com
} 
Resumen: El objetivo de este artículo es provocar reflexiones sobre el aspecto filosófico del juego del cuerpo del embaucador como un acto de resistencia al conocimiento hegemónico eurocéntrico. Propongo, por lo tanto, tratar el engaño como un gesto étnicoracial de desobediencia al colonialismo. Observo que este comportamiento referenciado por el terror está atravesado por deletreos corporales que generan otras lógicas epistemológicas además del cartesianismo. Dos preguntas subyacen a mis reflexiones en este artículo: ¿El juego corporal del sujeto se llamaría un embaucador, una estrategia filosófica para desobedecer los patrones de comportamiento coloniales? ¿Cuál sería la razón para que los términos, malemolencia y pelintra, que forman parte del vocabulario de la cultura afrobrasileña, se aborden de manera prejuiciosa y despectiva en los diccionarios de lengua portuguesa?

Palabras clave: Cuerpo; Malandro; Decolonial; Capoeira; Samba.

\section{LA PHILOSOPHIE DU MALANDRO: L'ESTHÉTIQUE D'UN CORPS ENCHANTÉ PAR LA DÉSOBÉISSANCE}

Résumé: Le but de cet article est de provoquer des réflexions sur l'aspect philosophique $\mathrm{du}$ jeu corporel du filou comme acte de résistance à la connaissance hégémonique eurocentrique. Je propose donc de considérer la supercherie comme un geste ethno-racial de désobéissance au colonialisme. J'observe que ce comportement afroréférencé est traversé par des orthographes corporelles qui génèrent d'autres logiques épistémologiques en plus du cartésianisme. Deux questions sous-tendent mes réflexions dans cet article: le jeu corporel du sujet serait-il appelé un filou, une stratégie philosophique pour désobéir aux modèles coloniaux de comportement? Quelle serait la raison pour laquelle les termes, malémolence et pelintra, qui font partie du vocabulaire de la culture afro-brésilienne, seraient abordés de manière préjudiciable et dérogatoire dans les dictionnaires de langue portugaise?

Mots-clés: Corps; Malandro; Décolonial; Capoeira; Samba.

\section{PASSO A PASSO, UM SINCOPADO PASSO}

Sou tocador de viola

E também sou doutor

Eu me chamo Zé Pelintra,

Sou malandro, sim senhor.

Salve a malandragem! Esta é uma das formas de saudar Seu Zé Pilintra nos terreiros de umbanda ou de catimbó. A malandragem, neste caso, é representada pela entidade de Seu Zé Pilintra ${ }^{2}$. Por isso começo saudando a quem deverá orientar cada passo

\footnotetext{
${ }^{2}$ Seu Zé Pelintra ou Zé Pilintra é uma entidade mítica conhecida nas rodas da Jurema, do Catimbó e da Umbanda carioca. Configura-se como a representação do malandro. Muitas são as histórias deste mestre das artimanhas e dos saberes corporais. Suas façanhas atravessaram toda região nordeste e vieram morar
} 
gingado na produção dessa escrita. As encruzilhadas que serão produzidas durante as tramas e trocas surgidas no decurso da leitura, deste texto, estão fundamentadas em encantamentos arquitetados por princípios filosóficos que gingam entre a noção de subalternidade e a produção de epistêmes geradas no corpo e pelo corpo do malandro. São ações que reverberam no chão da vida através de movimentos desobedientes, rastros de resistência, histórias de luta e rasteiras libertadoras contra os paradigmas coloniais.

Dito isto, confirmo que o chão dessa experiência cognitiva leva o nome de Brasil. Portanto, o objetivo deste artigo é demonstrar que o jogo de corpo, o jeito sincopado de agir como ser-no-mundo do malandro é um ato de resistência contra saberes hegemônicos que têm como base a racionalidade. Esses saberes eurocentrados negam o corpo em sua inteireza como um dos lugares atravessado por grafias psicofísicas, que geram outras lógicas epistemológicas para além do cartesianismo. A clássica separação entre mente e corpo tão difundida pelo pensamento euro-ocidental engendrou uma fissura ontológica entre o corpo e as lógicas socioculturais que atravessam este corpo.

Sendo assim, faz-se necessário ressaltar que o tema da malandragem é observado neste artigo sob a luz de princípios instaurados pelo jogo de capoeira e pelo molejo do corpo masculino ${ }^{3}$ no momento de sambar. Não serão observadas, neste artigo, outras manifestações afro-brasileiras como jongo, umbigada, maculelê etc. No entanto, as considero como parte de uma constelação filosófica que é atravessada pelo conceito de malandragem, ou seja, estas ações performativas fazem parte de um acontecimento cultural de resistência e de potente desconforto para os padrões éticos e morais do colonizador.

Uma representação deste desconforto causado pelo aspecto filosófico da malandragem é a forma como os termos pelintra e malemolência são abordados e classificados semanticamente nos dicionários de língua portuguesa, como veremos mais adiante. Baseado em um "modus" de vida que não pode ser controlado pelos padrões canônicos euro-ocidentais, o malandro incorpora em seu cotidiano os fundamentos básicos dessas duas expressões verbais.

entre os arcos da Lapa, no centro do Rio de Janeiro. Durante todo texto oscilarei entre a duas denominações. $\mathrm{Na}$ maioria das vezes o termo Pilintra estará diretamente relacionado ao tratamento dado a entidade.

${ }^{3}$ Enfatizo o jogo de corpo masculino por observar a luta, a partir da capoeiragem, no conflito com o olhar do colonizador. Não estou abordando o olhar erotizado do colonizador/a sobre o corpo negro, que já foi tema de alguns outros artigos, por não ser o foco desta pesquisa. 
Duas questões suleiam minhas reflexões neste artigo: Seria o jogo de corpo do sujeito chamado de malandro, uma estratégia filosófica para desobedecer aos padrões coloniais de comportamento? Qual seria a razão dos termos, malemolência e pelintra, que fazem parte do vocabulário da cultura afro-brasileira, serem abordados de forma preconceituosa e depreciativa nos dicionários de língua portuguesa?

Pois bem, as reflexões desenvolvidas no decorrer do texto estão organizadas em três tópicos. Na parte introdutória, Passo a passo, um Sincopado passo, busco fazer uma breve introdução da figura do malandro a partir do seu representante mítico e espiritual: Seu Zé Pilintra, além de apresentar o ponto de partida dos pensamentos que serão desdobrados no decorrer do texto. Na sequência desenvolvo em outros dois tópicos os fundamentos filosóficos da arte da malandragem: Jogo de corpo, a Malemolência como Metáfora da Vida e Estética Pelintra, uma Desobediência Colonial. A ideia é, como afirma o filósofo e pesquisador Eduardo Oliveira, demonstrar que "o corpo não é simplesmente fonte de todo movimento e ação". Mas “(...) um acontecimento que inaugura a existência" (OLIVEIRA, 2007, p.103), portanto serão aprofundadas as relações entre o corpo na condição de malandragem e a produção de um comportamento pautado em uma forma de pensar o mundo que se materializa no jogo de capoeira e nas rodas de samba. Enfim, esse corpo em movimento age de forma transgressora, debochada, opondo-se a um comportamento determinado por regras colonizadoras. Observo que a ludicidade é uma caraterística fundante dessas práticas afrodiaspóricas, muitas vezes ela, a ludicicidade, pode servir como um elemento dissimulador das reais intenções envolvidas no jogo.

No último tópico me debruço sobre a importância política e histórica destas ações de resiliência e resistência que se perpetuaram através da capoeira e do samba e fazem parte do cotidiano identitário da população brasileira até os dias de hoje. Como afirma a pesquisadora Claudete Nogueira em seu artigo: "O batuque de umbigada do interior de São Paulo: Tradição oral, memória e ancestralidade”. Nas palavras da autora;

(...) ao contrário do que se acreditou durante muito tempo, em momento algum, transformaram-se em objetos. Esses grupos negros, mesmo escravizados, contribuíram de maneira significativa na formação social das regiões onde se fixaram, ora por meio da reafirmação de sua cultura ora pela construção do seu processo de identidade (NOGUEIRA, 2019, p.77). 
Estas ações podem ser entendidas como estratégias contra coloniais que "negaceiam"4 com a sociedade outras noções espaços-temporais configuradas a partir de expressões performativas de afirmação identitária que são alicerçadas em processos artístico-culturais.

Para dar continuidade as minhas reflexões, antes de fazer uma introdução histórico-política do Seu Zé Pilintra, proponho que adentremos, portanto, ao tópico que problematiza a deturpação semântica do termo malemolência apresentada pelos dicionaristas da língua portuguesa. Enfatizo que esta palavra é apresentada nos dicionários de língua portuguesa de forma pejorativa, preconceituosa. Neste artigo a ideia de jogo de corpo é demarcada incialmente pela malemolência, postura corporal desafiadora e que produz fricções com a ideia de colonialidade. Então, leitores e leitoras, o jogo continua. Nós balançamos daqui vocês balançam de lá e seguimos na ginga com as palavras.

\section{Jogo de corpo, a malemolência como metáfora da vida.}

\section{Gingo, logo (r) existo!}

Lau Santos

O termo malemolência, maneira de se movimentar associada ao malandro, visto sobre a ótica colonialista, foi introduzido nos dicionários brasileiros/portugueses como falta de disposição, preguiça, falta de empenho e apatia. Alguns lexicólogos definem malemolência como: substantivo feminino definido por ausência de disposição: moleza, indisposição, calma excessiva; falta de empenho; fleuma; pachorra. Ao vasculhar diversos dicionários, descobri que malemolência é uma palavra classificada de forma pejorativa e designa características de um "alguém" preguiçoso, muitas vezes, metido a esperto, ludibriador. Garimpando um pouco mais, entre os vocabulários designados para nomear este "alguém", descubro que o sujeito com estas características, não é considerado como um "cidadão de bem"5 para o convívio social. É importante observar

\footnotetext{
${ }^{4} \mathrm{O}$ termo negaceia é por mim utilizado no sentido de definir a relação entre a dissimulação das reais intenções do sujeito no jogo da vida, ou seja, o sujeito pratica a condição de malandragem contra as práticas opressivas do colonizador. A negaça é uma estratégia bastante utilizada no jogo de capoeira com o objetivo de surpreender o oponente. Neste texto negaciar é um neologismo derivado da junção entre negociar + negaça $=$ negaciar .

5 Termo da moda no governo atual. É bastante utilizado pelos conservadores para definir dentro de uma perspectiva elitista as diferenças étnicos-raciais, sociais e de gênero em nosso país. No governo conservador o tal "cidadão de bem" é representado homem branco e Hétero Cis.
} 
como o peso semântico dado a este substantivo tem como finalidade subalternizar, desonrar, difamar a imagem deste cidadão malemolente que geralmente é definido pelo discurso dominante como uma figura masculina da população negra.

Pois bem, investigando dicionários mais atualizados, neste caso o Dicionário Aurélio da língua portuguesa, detectei uma preocupação com esta visão pejorativa dado ao termo em outros dicionários. No entanto, pude perceber que as definições apresentadas por este dicionarista demonstram uma certa confusão semântica para classificar, ou melhor, dar sentido à palavra malemolência. Por vezes, o termo é apresentado ainda dentro de um contexto semântico pejorativo como: moleza ou preguiça; subterfúgio e pretexto. Em outras classificações Aurélio Buarque de Holanda, creio que mediante esta necessidade de atualizar suas observações semânticas, afirma que malemolência seria, portanto, um misto de elegância, malícia e esperteza. Buarque de Holanda, o autor do Aurélio (forma como também chamamos o dicionário) demonstra em outra oportunidade a existência de uma aproximação musical do vocábulo com a história da música popular brasileira. Assim, define o vocábulo mediante sua importância no campo da música e atribui ao mesmo uma relação semântica demarcada pelo ritmo ou a dança do samba. Segundo este estudioso dos léxicos, este termo pode ser definido, segundo um tipo de comportamento ou movimento corporal.

Sendo assim, com base nestas observações sobre o corpo do negro, malemolência se caracteriza como trejeitos dos malandros de antigamente: malandragem ou ritmo bamboleante de alguns cantores de samba. Reconheço, portanto, neste autor uma tentativa, ainda que tímida, de demonstrar um outro ponto de vista. Porém, observo que esta definição está posta como uma das últimas na ordem apreciativa que dá sentido ao vocábulo e é uma visão localizada culturalmente no mundo do samba e no comportamento contextualizado da personagem do malandro. À medida que o samba passa a ser aceito como expressão musical brasileira, o comportamento do malandro, ainda que com muitas restrições, passa, então, a ser visto pela sociedade brasileira, como parte de um contexto musical específico. Ainda que marginalizada, a palavra malemolência ganha "status" de expressão cultural. Observo que é no corpo do negro sambista e/ou capoeirista, neste caso, que se aglutinam alguns princípios fundamentais das diversas cosmovisões do continente africano. Para o filósofo Eduardo Oliveira, "é preciso ler o texto do corpo para vislumbrar nele a cosmovisão que dá sentido a história dos africanos e afrodescendentes espalhados no planeta" (OLIVEIRA, 2007, p.101). Abro o jogo, puxo minha ginga e afirmo que foi 
a resiliência do samba como expressão cultural afro-brasileira, oriunda das camadas populares e marginalizadas, que se impôs e sobrepujou a visão pejorativa difundida pela classe dominante. Penso que, seja esta uma das razões basilares que levou Aurélio Buarque de Holanda, entre outros dicionaristas, a reconfigurar, de alguma forma, as interpretações preconceituosas dadas ao termo malemolência e vislumbrar a possibilidade de outros pontos-de-vista. O corpo, então, passa a ser valorizado como uma potência cultural capaz transformar a lógica semântica estabelecida pelos lexicólogos. O corpo reconfigura a linguagem dominante e reinventa os paradigmas linguísticos da língua portuguesa. Assim como nos demonstra Oliveira:

Como o corpo é um texto dinâmico e a matriz africana um dinâmico movimento, é no movimento do corpo que vislumbro a possibilidade de uma leitura de mundo a partir da matriz africana, o que implica em decodificar uma filosofia que se movimenta no corpo e um corpo que se movimenta como cultura. O corpo ancestral é a reunião desta filosofia, desta cultura bem como o resultado desse movimento de contatos e conflitos que se deram e se dá na esfera social, política, religiosa e corporal (OLIVEIRA, 2007, p.101).

Pois bem, no dicionário do samba, malemolência é o ritmo gingado, o gesto malicioso, o jogo de atitudes, o molejo de corpo, ou seja, uma maneira de se portar na sociedade. Segundo Muniz Sodré, o jogo de corpo é inerente à construção rítmica do samba devido a um vazio sonoro a ser preenchido corporalmente:

De fato, tanto Jazz quanto no samba, atua de modo especial a síncopa, incitando o ouvinte a preencher o tempo vazio com a marcação corporal - palmas, meneios, balanços, danças. É o corpo que também falta - no apelo da síncopa. Sua força magnética, compulsiva mesmo, vem do impulso (provocado pelo vazio rítmico) de se completar a ausência do tempo com a dinâmica do movimento no espaço (SODRÉ, 2007, p. 11).

É, portanto, desta necessidade rítmica que podemos pressupor a origem do molejo de corpo do malandro definido de várias formas nos dicionários pesquisados. Ou seja, o corpo negro entra em harmonia com a parte musical que é tocada ao completá-la, preenchê-la. A síncopa ${ }^{6}$ ou síncope é essa batida que "falta", que gera um vazio nos ritmos de matriz africana, para ser preenchido por palmas, danças e jogo de corpo. A integração entre corpo e música é o que produz a cadência na movimentação corporal da malandragem. Um jeito de corpo, um meneio corporal é o que determina o deslocamento de forma sincopada do malandro. No que diz respeito à presença de ser-no-mundo, o jogo

\footnotetext{
${ }^{6}$ Assim está grafado por Muniz Sodré. Verificamos que na atualidade encontramos este termo grafado como síncope. Sincope é o elemento rítmico que consiste no deslocamento da acentuação da parte forte do tempo para a parte fraca do tempo.
} 
sociológico plasmado na sociedade por este sujeito pode ser percebido pela materialização desta experiência rítmica da síncope no corpo do mesmo mediante a malemolência. Esta ginga do sujeito, por sua vez, pode ser percebida pelo outro, mediante a produção de corporeidades e corporalidades desobedientes, isto é, que desafiam os paradigmas comportamentais colonizadores.

A malandragem neste texto é vista como uma maneira filosófica de existir. Uma forma de produção de presença que se caracteriza no jogo do "eu" com o "outro", ou seja, na capacidade deste sujeito organizar sua visão criativa de mundo, seus fundamentos usam como suporte movimentos psicofísicos de outra ordem. A sinuosidade e a circularidade determinam o caminho das pedras. Um de seus objetivos é burlar normas de conduta baseadas em orientações cartesianas, opressoras, coloniais, racistas e hegemônicas em que "o negro é representado como o protótipo de uma figura préhumana, incapaz de escapar de sua animalidade, de se autoproduzir $\{\ldots\}$. (MBEMBE, 2018, p. 41).

Neste contexto o samba e a capoeira, funcionaram e funcionam ainda hoje como estratégias de sobrevivência cultural, física e de autoafirmação. As práticas opressivas de poder representadas por uma ideologia de branquitude devem ser combatidas, assim como uma ideologia de um conhecimento universal, hegemônico, com base no cartesianismo euro-ocidental. A população negra na condição determinada pela diáspora africana, atuou e atua assentada nos fundamentos ancestrais e nos rastros históricos de uma luta de resistência contra o racismo e as estruturas dominantes de poder. E é assim que agiu e age o malandro. É nas entrelinhas, nas frestas do poder dominante que acontece o jogo de dentro.

A cada jogo em uma roda de capoeira, experiências singulares de utilização do corpo são reconfiguradas tendo como base os princípios filosóficos da malandragem. Sodré por sua vez comenta a importância do samba para além de sua técnica musical, como elemento de manutenção da fé em se manter vivo e ao mesmo tempo em ser um instrumento de luta de afirmação cultural. Comenta Sodré:

$\mathrm{Na}$ técnica dessa forma musical, o ritmo ganha o primeiro plano (daí a importância dos instrumentos de percussão), tanto por motivos religiosos quanto por atestar o domínio do homem sobre o tempo: o tempo capturado é afirmação, meio de duração da vida e de elaboração simbólica da morte, que não se define a partir da passagem incorrigível do tempo. Cantar/dançar, entrar no ritmo, é como ouvir os batimentos do próprio coração - é sentir a vida sem deixar de nela se reinscrever simbolicamente a morte. (SODRÉ, 2007, p. 23.) 
O sagrado e o profano se encontram representados na luta simbólica contra a morte, como disse Sodré, e se reconfiguram em trejeitos de corpo, danças e cantos. Essa é uma forma de resistência agenciada, ou melhor, negaciada ${ }^{7}$ através de sua resiliência aos paradigmas comportamentais eurocentrados. Dentro dessa perspectiva de transgressão, o corpo do negro trazido como escravo se torna um elemento fundamental de comunicação e o cantar/dançar no ritmo da percussão, interage com os batimentos do coração e faz deste corpo um lugar de libertação.

Em um outro artigo em que busco analisar a potencialização da presença cênica e suas influências ancestrais, abordo essa questão que acredito dialogar com a afirmação de Sodré (1998). Comento que a materialização das informações ancestrais trazidas pelo corpo-arquivo (TAVARES, 1997) se revelam a partir de um estado mental que age durante a produção de corporeidades:

[...] O valor transgressor da postura comportamental dos ancestrais africanos, na condição de escravizados, foi determinado pela fé, pela luta para sobreviver, de modo que a conviç̧ão durante uma ação estava diretamente relacionada a capacidade potencial de realização e de credibilidade frente ao outro (SANTOS, 2018, p.12).

Os fundamentos comunicacionais e geradores de corpos transgressores no campo filosófico da malandragem tem como base a sua própria sobrevivência. O ritmo e o tempo capturados e reinventados entre a ludicidade e os princípios de luta contra os mecanismos coloniais atravessam o corpo deste sujeito como uma potência de afirmação de sua presença no mundo. Para os pesquisadores Luiz Simas e Luiz Rufino, estes territórios conceituais estão demarcados por tensões geradas durante os cruzamentos com as epistemologias eurocentradas:

Os conceitos emergentes de uma epistemologia subalterna visam o deslocamento da primazia do modelo de racionalidade fundado e gerido por uma política racista/colonial. Assim, a prática do cruzo é transgressiva de atravessamento, sucateamento e antidisciplina (SIMAS; RUFINO, 2018, p. 27).

A visão que nos é transmitida sobre a ideia de malandragem tem como objetivo nos afastar de qualquer identificação com a figura do malandro. Observo que a noção de malandro que abordo não está relacionada a visão contemporânea de "bandido", ainda

\footnotetext{
${ }^{7}$ Negaciar é um neologismo que utilizo para fundir a relação da negaça, movimento de recuo na capoeira, com negociar, ou seja, instaurar outras estratégias de sobrevivência com base nos saberes da cosmovisão africana.
} 
que eu saiba da complexidade social e política desta afirmação. A filosofia da malandragem defendida neste texto é demarcada por valores e crenças das cosmovisões africanas que se (re) organizaram em território brasileiro a partir da condição de diáspora e passam a ser compreendidas como estratégias socioculturais de luta.

Viver à margem da sociedade e produzir poéticas corporais, corporeidades, que se transformam e se transformarão, a cada dia, em armas de resistência contra o racismo e contra práticas políticas de subalternização são desafios como o da a metáfora vida-demalandro, apresentado neste texto. Meu olhar de artista-malandro, malandro-capoeirista e de malandro-sambista, neste caso, se faz gestus ${ }^{8}$ e procura riscar no chão da sociedade as qualidades existenciais de um ser que habita um tempo-espaço que não condiz com os paradigmas colonizadores do capitalismo.

Como afirma Achille Mbembe, “A vida é um mistério, pois, ao fim e ao cabo, é feita de nós" (2018, p.231), o malandro transporta esta máxima para seu corpo e a executa com suas ações, pois "O acontecimento por excelência é sempre flutuante” (MBEMBE, 2018, p. 231). Para cada jogo, para cada samba um novo desafio, um novo encontro, enfim, uma nova leitura de mundo. O ritmo da percussão rege o corpo desse sujeito e seu caminhar sincopado. Enfim, seu coração é o primeiro tambor, aquele que o marca-passo, que o impulsiona para um campo de possibilidades. Esse caminhar sincopado se materializa como ação sociocultural e política nas encruzilhadas, lugar onde se reinventa e se dá continuidade à vida. É, portanto, essa ação comportamental, pautada pela força da presença do corpo negro em movimento que assusta, que mete medo nas estruturas de poder. Por esta razão, podemos perceber que qualquer envolvimento de um determinado sujeito com os princípios da malandragem sempre foi rechaçado e oprimido pelas camadas dominantes da sociedade brasileira.

Pois bem, no intuito de compreender a função do Mestre da Malandragem, entendido neste texto como o representante da luta de/colonial e como um dos mentores filosóficos da pesquisa de pós-doutorado ${ }^{9}$ em dança que desenvolvi durante os anos de 2018 e 2019, passarei, então, para o próximo tópico que aborda de forma breve, sem interesse de fazer um relato histórico, a figura do Seu Zé, um ser-malandro-encantado, um encantado-ser-malandro que habita o imaginário cultural brasileiro. A representação

\footnotetext{
8 O termo gestus, é entendido, neste caso, à luz do dramaturgo e diretor alemão Bertold Brecht, ou seja, como uma atitude global de uma pessoa ou de um grupo envolvidos em relações inter-humanas.

${ }^{9}$ Esta pesquisa foi por mim desenvolvida durante os anos de 2018 e 2019 no Programa de Pós-Graduação em Dança da Universidade Federal da Bahia.
} 
física deste personagem e sua potência simbólica instaurou normas comportamentais desobedientes e contra coloniais, que se perpetuam pelas ruas, rodas de samba, rodas de capoeira, pelos palcos e pelos terreiros de Catimbó e Umbanda, na qual recebeu o título de Mestre da Ciência Encantada. Salve Seu Zé Pelintra!!

\section{Estética pelintra e desobediência colonial}

"Os caminhos retos são limites a serem transgredidos” Luiz Simas, Luiz Rufino

Antes de adentrar ao complexo universo do malandro Zé Pelintra, farei um breve recorrido sobre o que desenvolvi nos encontros e práticas corporais durante minha pesquisa de pós-doutorado em dança desenvolvida no PPGDança/UFBA ${ }^{10}$. Nesta pesquisa procurei desenvolver exercícios corporais fundamentados na filosofia da malandragem. As bases desses exercícios corporais estão alicerçadas em deslocamentos com passos de samba e ou com movimentos de capoeira. São exercícios, de certa forma, simples que visam manter o participante em constante estado de alerta. O intuito é potencializar a presença do participante no jogo, na vida, na roda, na cena. Neste sentido, foi criado um organograma (Fig.1) tendo como suporte exercícios corporais que usam como base para potencialização da presença a ginga, o jogo de corpo e outros princípios sinuosos da arte da malandragem.

As variantes situacionais foram definidas pela relação que se estabelecia no encontro com o outro em situação de jogo. A ruptura com os caminhos retos é um dos princípios da malandragem que foram utilizados na construção dos jogos corporais. Todos caminhos traçados no espaço, assim como a produção dos movimentos corporais, que por sua vez geravam as ações, fazem uso do princípio da sinuosidade, da ondulação e da circularidade. Como afirmam os pesquisadores cariocas Luiz Simas e Luiz Rufino (2018, p. 83), “O que importa é saber chegar em qualquer banda: o bom malandro não explana, chega sem ser visto e sai sem ser lembrado.” O jogo entre ausência e presença é definido pela observação dos participantes no momento de entrar e sair do acontecimento cênico. Essa capacidade de observação, definida por uma total concentração, uma atenção

\footnotetext{
${ }^{10}$ A pesquisa referida é intitulada Elinga, a Presença Cênica: as Práticas Performativas Afrodiaspóricas e a Decolonialidade no Processo criativo e pedagógico da (o) Performer/Dançarina (o) foi desenvolvida no PPGDança na Escola de Dança da Universidade Federal da Bahia. A supervisão é da Professora Dra. Amélia Conrado. Para informações sobre a pesquisa, ler o artigo "Émi, Ofó, Asé: A Presença Cênica e a Sutileza Performativa das Mulheres do Asé. Este artigo foi publicado nos ANAIS da ABRACE 2018.
} 
integral com instante no momento do jogo é o que se definiu, durante os processos criativos, como a instauração de uma possível Estética Pelintra. Uma estética em que o corpo é o local primordial do acontecimento; os deslocamentos corporais, assim como todo e qualquer movimento gerado por este corpo devem fugir das linhas retas; as cantigas ou textos devem ser compreendidos, em sua profundidade, pelo não-dito; a ritualização do instante é argumento crucial para potencializar a presença; a hibridação de linguagens é uma máxima e todas ações(transnegrações) devem dialogar com o arabaque. ${ }^{11}$ Neste sentido, os estudos desenvolvidos durante a pesquisa tinham como objetivo compreender de que forma o impulso, marcado pela síncopa, nas práticas culturais afrodiaspóricas pode ser um fator determinante na relação presença-corpoancestralidade-decolonialidade.

Pois bem, a outra abordagem feita durante a pesquisa de pós-doutorado Elinga ${ }^{12}$, sobre a figura mítica do Seu Zé Pilintra, trata da importância de seu comportamento como ato de insubordinação e desobediência aos padrões comportamentais coloniais. Como já foi dito no início deste texto, a primeira forma de estudar esta figura mítica como uma personagem transgressora foi buscar a definição deste substantivo nos dicionários de língua portuguesa.

Antes de começar a dissertar sobre a personagem mítica e mística do Seu Zé Pilintra, quero compartilhar com vocês que retornei, mais uma vez, aos dicionários a fim de descobrir como é definido pelos lexicólogos da língua portuguesa a palavra pelintra. Pois bem, as definições encontradas na literatura dizem que este termo é um substantivo masculino e feminino que significa pessoa pobre e mal trajada, com pretensão a exibirse, pessoa com desejo de ostentação. Adjetivado o substantivo gerou as palavras malajambrado, malvestido, que pretende fazer boa figura. Observo, portanto, que estas descrições depreciativas usam como base de análise o modo de se vestir do sujeito. Estas descrições e análises estão diretamente ligadas à figura do malandro. Neste sentido, é importante ressaltar que o traje, da forma como é utilizado pelo malandro, não se ajusta à ideia de subordinação comportamental e estética imposta pelos padrões colonialistas. No livro O Rei da Lapa, o pesquisador e Professor Gilmar Rocha traça uma reflexão

\footnotetext{
${ }^{11}$ Esta expressão foi cunhada por mim para definir a relação do corpo do sujeito, em situação de jogo, com o ritmo externo. Neste sentido, na estética pelintra é fundamental a atenção dada para com a combinação entre musicalidade interior e musicalidade exterior durante a produção de presença.

12 A palavra Elinga, na língua umbundu ou umbundo é uma língua do tronco bantu falada pelos ovimbundos/Angola e quer dizer ação.
} 
crítica sobre o traje do malandro como um símbolo, uma expressão concreta de seu "empoderamento". Ou ainda, a consolidação de sua imagem para o imaginário brasileiro.

Segundo este autor:

É sabido que o vestuário designa um tipo de linguagem simbólica, um importante modo de significação cultural. Em particular, o vestuário do malandro pode ser visto como uma narrativa por meio da qual podemos ler e ver aspectos fundamentais do processo de construção da sua identidade social. (ROCHA, 2005, p.176).

Sendo assim, o ser-malandro não é uma questão de estilo, a preocupação estética do malandro faz parte de uma ideia de resistência e é a produção de um código comportamental. O sistema colonial atua nas esferas de poder e de domínio de nossas subjetividades. A definição semântica dada à palavra pelintra pelos dicionários, como foi visto no parágrafo anterior, mais uma vez se configura como uma atuação racista dos dicionaristas, baseada em normas comportamentais sobre a utilização de determinado vestuário. Quem ditou essas normas? O malandro, como bem afirma Gilmar Rocha, nega este vestuário e produz uma narrativa outra, mediante a sua maneira singular de se vestir e com isto busca construir sua identidade social. Uma identidade que negaceia com os trajes da sociedade colonial. O terno, sinônimo de respeito, de "Sinhô Doutor", é utilizado de forma reconfigurada. O "Bom Malandro" o utiliza na cor branca, com uma gravata vermelha, um chapéu panamá e um sapato bicolor. O padrão estatutário de "dotô" é desafiado. Uma negação a determinada classificação étnico-racial imposta pela noção de bipoder é problematizada. O sociólogo peruano Anibal Quijano nos demonstra de que forma a colonialidade age para padronizar esta relação de poder:

A colonialidade é um dos elementos constitutivos e específicos do padrão mundial de poder capitalista. Se funda na imposição de uma classificação racial/étnica da população do mundo como pedra angular do dito padrão de poder e opera em cada um dos planos, âmbitos e dimensões materiais e subjetivas, da existência social cotidiana e da escala social. Origina-se e mundializa-se a partir da América (QUIJANO, 2000, p. 342).

O texto de Quijano (2000) nos demonstra de que forma esta colonialidade opera e se mundializa A rua, para o malandro, é um mundo e as lutas contra a colonialidade e seus elementos específicos de dominação fazem parte deste seu mundo. Nas encruzilhadas os saberes do corpo, dizem o não dito. O corpo do malandro é encantado 
pela desobediência e atua nas frestas impostas pelos setores burgueses da sociedade. Tal qual Exu Bara ${ }^{13}$ (Elegbara), o dono do corpo, o malandro se apropria de seu corpo para revelar ou invisibilizar sua Presença. Ele entra saindo e sai entrando ${ }^{14}$. Seu corpo vive de forma "relaxada" o instante de atenção. Em outro artigo falo da importância de se ritualizar o instante ${ }^{15}$ para se potencializar a presença. A ritualização do instante na arte filosófica da malandragem seria, portanto, como já foi dito acima, em outras palavras, a capacidade deste sujeito de se reinventar na medida que descobre o ambiente na qual está inserido. A ritualização do instante é delineada pela efemeridade do acontecimento que é intensificado em sua potência máxima pela maneira como o malandro abraça a vida. Vida e morte fazem desta encruzilhada, enfim, fazem parte deste campo de possibilidades na qual o corpo é um dispositivo biológico, cultural e subversivo.

A mobilização deste corpo é pautada pela estrutura rítmica da síncope, pisa fraco, pisa forte. "É seu impulso que leva o corpo a garimpar a falta" (SODRÉ, 2007, p.68). Seus movimentos configuram-se a partir dessas bases instáveis em que os pés quase flutuam sobre o chão, quando se deslocam. A intensidade das ações desse sujeito atravessa as grades da carceragem colonial e ganha corpo nas ruas como transnegrações ${ }^{16}$, termo que utilizo para definir o poder subversivo, de um pensamento que tem base no corpo, a partir das cosmovisões de matriz africana, e se define pela capacidade do sujeito organizar sua presença em um determinado contexto espaçotemporal.

Essa forma de trocar conhecimento com o mundo conserva traços ancestrais de uma gestualidade que se (re) constrói na diáspora africana. O que se sabe é que a base ancestral deste malandro, foi construída culturalmente pela desobediência, ou seja, em oposição a qualquer espécie de realeza dominante, colonialista. Na rua ele é o Rei, aquele que desestabiliza a lógica cartesiana do colonizador, essa do "penso, logo existo", tida

\footnotetext{
${ }^{13}$ Exu Bara é o exu dono corpo, também conhecido na cultura fon/jeje como Vodun Elegbara. A expressão bara significa corpo. Ele é o Senhor da irreverência e das artimanhas.

${ }^{14}$ Esta expressão representa o que fazem alguns jogadores de capoeiras na hora do jogo, no momento de responder à pergunta corporal feita pelo outro jogador. Em uma conversa com Mestre Cobra-Mansa, dizíamos que esta percepção de tempo e de espaço faz parte de uma lógica corporal instaurada no universo do jogo de capoeira. Segundo o Mestre Cobra-Mansa a grande dificuldade é traduzir esta lógica em palavras em outras línguas para que o aprendiz de capoeira capte este aspecto filosófico do jogo.

${ }^{15}$ Para maiores informações ler o artigo: SANTOS, Lau. Ėmí, Ofò, Asé: A Presença Cênica e a Sutileza Performativa da Dança das "Mulheres do Asé", presente nas referências deste texto.

${ }^{16}$ Ações transgressoras, ou seja, as transnegrações são definidas, por mim, como essas ações corporais desobedientes, experiências físicas, carnais, estéticas, religiosas, socioculturais e políticas nas quais suas corporeidades e corpografias foram geradas em tensão com as correntes do processo colonial, a partir das cosmovisões de matriz africana, durante o processo da afrodiáspora.
} 
como forma hegemônica de entendimento de mundo. No contra fluxo desta lógica o malandro se impõe dizendo através do silêncio a sua máxima: "gingo, logo (r) existo". Esta maneira de atuar na sociedade nos mostra o desprendimento deste sujeito dos padrões determinados pela naturalização dos conhecimentos euro-ocidentais como forma única de entender e conhecer o mundo.

A filosofia da malandragem nos direciona para a ideia de malemolência, que tem na representação física, corporal do malandro os aspectos que definem, o que tenho chamado por estética pelintra. É difícil separar a figura do malandro da capoeira, do samba, da macumba e dos botequins cariocas. A junção dessas expressões culturais atravessa a personalidade desse sujeito "boa praça" e sedutor que risca seus passos enquanto abre caminhos e gera lugaridades $^{17}$ (SANTOS, 2018, p.4282), a partir de sua presença nas rodas por onde passa. Em uma belíssima definição da arte da malandragem, os pesquisadores da cultura carioca Luiz Simas e Luiz Rufino descrevem o jeito de ser do malandro e sua arte mandingueira. “A ginga é a sedução que abre caminho. Para o destronamento, afinal rasteira sempre foi um dos mais belos golpes, coisa fina. Para quem a recebe não há se quer susto, quando se procura a cadeira já não mais acha, tombo na ladeira" (SIMAS; RUFINO, 2018, p.85). Com seu corpo-fechado, seu corpo-em-festa e, “em um mundo que padece de desencantamento a poética da malandragem é ainda lida como algo menor, à margem dos pressupostos e normas que regimentam a sociedade zeladora de certezas, do pecado e dos bons costumes". (SIMAS; RUFINO, 2018, p.95). Seu Zé Pilintra desafiou e, ainda, desafia a colonilalidade do poder quando nos mostra as artimanhas de sua filosofia com uma boa rasteira que "(...) cumpre a ética do jogo, (e) é poesia que se inscreve no limite do vazio deixado pelo outro com quem se joga" (SIMAS; RUFINO, 2018, p.85). Como já foi visto, anteriormente, é no espaço deixado pela síncopa que o corpo age. É no jogo sutil de pernas e quadril que se produz o passo de samba onde o malandro mostra sua elegância, mas é também deste mesmo jogo de pernas, quadril e negaças que o malandro disfere uma cabeçada, uma banda ou uma rasteira no seu oponente.

\footnotetext{
17 Termo resgatado da geografia e reconfigurado pelo autor deste artigo em 2016 para indicar uma capacidade do sujeito em definir seu lugar no espaçotempo e expandir sua presença cênica alimentada pelas transições entre o èmí, o ofó e o asé. O domínio desta condição temporal, na linguagem deste pesquisador que vos fala, produz o èmi wá (presença cênica conectada com a força vital, o encantamento e o sopro da vida). Para mais informações ler o artigo que saiu nos ANAIS da ABRACE em 2018, colocado nas referências.
} 
O importante, neste sentido, é o outro lado do conhecimento, a forma como essas ações, ou melhor essas transnegrações são executadas, a sinuosidade de cada movimento corporal e a circularidade como fundamento de uma lógica de ação. Sua potência transgressora implica um certo entendimento do caráter complexo desse sujeito artista/malandro/encantado que funde vida e morte, o visível e o invisível, dança e luta, teatro e performance, alegria e guerra, sagrado e profano em suas coreografias contra coloniais. Na manhã, sorrateiramente sua imagem se instaurou no imaginário do povo brasileiro.

A capoeira, o samba e outras expressões culturais da afro-diáspora, armas de resistência social e poética, atravessaram séculos oceânicos até ancorarem no século XXI. Hoje, fazem parte de pesquisas artísticas e acadêmicas. Meu interesse em desenvolver um estudo sobre a presença, ou melhor, sobre a presença cênica me fez perceber que diversas linguagens artísticas como: teatro, dança, artes visuais, contação de histórias, canto e música se hibridizam nas práticas artístico-culturais de cosmovisão africana, diferentemente do entendimento que nos é apresentado como ideia de arte, definida por paradigmas eurocentrados. A noção de arte que quase-sempre nos foi e é apresentada tem como base a separação dessas linguagens de maneira absoluta, ainda que em sua origem greco-romana não tenha sido compreendida dessa forma. A noção de espaço e de tempo também se diferem, no que diz respeito às experiências artísticas de matriz africana, nas quais a circularidade espacial e a efemeridade do acontecimento cênico atuam de forma complementar. As relações entre as mesmas são entendidas como potencializadoras da força presencial instaurada através do encontro entre os corpos dos participantes dessa experiência estético-cultural.

Tudo isto acontece na linha de fronteira que divide as dimensões do material e do imaterial, do objetivo e do subjetivo, do ficcional e do real. Enfim, considero que com esse jeito sincopado de agir, de deslocar seu corpo como ser-no-mundo, o malandro com sua arte da presença, produz um discurso traduzido em suas práticas que são, por este autor, compreendidas como respostas desobedientes ao colonialismo. A observação da atuação deste sujeito, o malandro, no campo social se tornou um princípio fundante de minhas pesquisas artísticas no campo da performance, do teatro e da dança que segue aberta como um campo de investigação artístico-filosófico, tal qual o movimento da ginga. A fala cantada do malandro acontece com seu corpo em movimento. O resto? $\mathrm{O}$ 
resto é uma ladainha bem cantada no pé do berimbau. Iê, Salve meus Mestres! Iê, vamos jogar, camará!

Capoeira é defesa, ataque, ginga de corpo e malandragem!!!

SALVE A MALANDRAGEM!

Figura 1: Organograma da Transnegração do Malandro

\section{ELINGA}

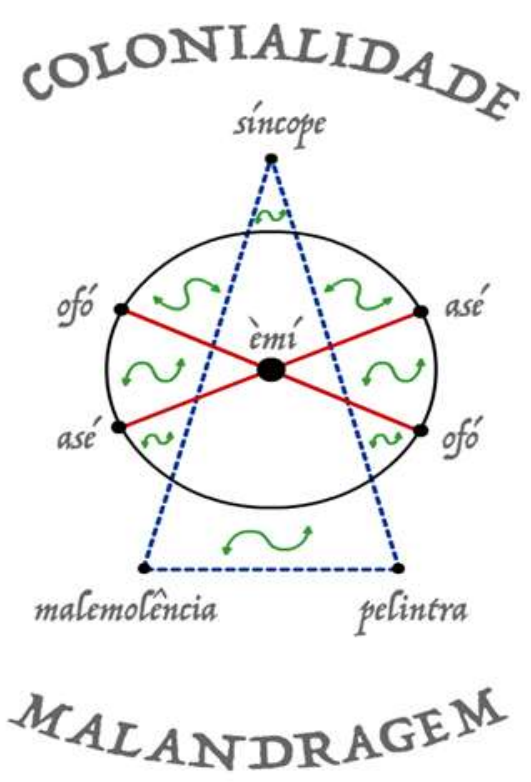

Fonte: Própria (2019)

As palavras apresentadas fazem parte das línguas africanas: umbundu e iorubá.

Elinga = Ação. O que fundamenta o ato de transgredir. (umbundu)

Èmí = O sopro de vida. O que mantém o corpo vivo. (iorubá)

Ofò $=$ O encantamento, a intenção. (iorubá)

Àse/Asé ${ }^{18}=$ A força vital, a materialização da ação. (iorubá)

\section{REFERÊNCIAS BIBLIOGRÁFICAS}

MBEMBE, Achille. Crítica da Razão Negra. Tradução: Sebastião Nascimento, São Paulo: N-1 Edições, 2018.

\footnotetext{
${ }^{18}$ A grafia da palavra àse ou asé e feita dessas duas maneiras por opção do autor. Minha primeira intenção é descolar essas grafias da grafia massificada pelo ritmo baiano de nome: axé. A segunda é uma aproximação a grafia original iorubá àse, que leva dois pequenos pontos embaixo das letras "s" e "e". A terceira forma se consagrou como forma usada em minhas anotações.
} 
MIGNOLO, Walter. Desobediência epistémica: retórica de la modenidad, lógica da colonialidad y gramática da descolonialidad. Buenos Aires: Ediciones del signo, 2010.

OLIVEIRA, Eduardo David. Filosofia da Ancestralidade: Corpo e Mito na Filosofia da Educação Brasileira. Curitiba: Editora Gráfica popular, 2007.

PELINTRA, Seu Zé. Malandragens. Rio de janeiro: Vida, s.d.

QUIJANO, Aníbal. Colonialidad del saber: eucentrismo e ciências sociales, Perspectivas Latinoamericanas. Buenos Aires: CLACSO, Consejo Latinoamericano de ciências sociales, 2005.

ROCHA, Gilmar. O Rei da Lapa - Madame Satã e a Malandragem Carioca, Rio de Janeiro: 7 Letras, 2004.

SANTOS, Lau. Ėmí, Ofò, Asé: A Presença Cênica e a Sutileza Performativa da Dança das "Mulheres do Asé". ANAIS DA ABRACE, v.19 - n.1, 2018. p. 4272 - 4292.

SIMAS, Luiz Antonio. RUFINO, Luiz. Fogo no Mato: A ciência encantada das macumbas. Rio de Janeiro: Mórula, 2018.

SODRÉ, Muniz. Samba: o dono do corpo. Rio de Janeiro: Mauad, 2007.

SOUSA NOGUEIRA, Claudete. O BATUQUE DE UMBIGADA DO INTERIOR DE SÃO PAULO TRADIÇÃO ORAL, MEMÓRIA E ANCESTRALIDADE. Revista da Associação Brasileira de Pesquisadores/as Negros/as (ABPN), [S.1.], v. 11, n. Ed. Especi, p. 73-86, out. 2019. ISSN 2177-2770. Disponível em: $<$ http://abpnrevista.org.br/revista/index.php/revistaabpn1/article/view/732>

TAVARES, Julio. Educação Através do Corpo: a representação do corpo nas populações AfroAmericanas. In: SANTOS, Joel Rufino dos (org.). Revista do Patrimônio, Negro Brasileiro Negro. Edição IPHAN. n.25, Brasília: 1997. p. 216-221.

Recebido 30/11/2019

Aprovado em: 30/01/2020 